\title{
Perivascular adipose tissue modulates vascular function in the human internal thoracic artery
}

\author{
Yu-Jing Gao, MD, PhD, ${ }^{a}$ Zhao-hua Zeng, MD, ${ }^{a}$ Kevin Teoh, MD, Arya M. Sharma, MD, PhD, ${ }^{c}$ Labib Abouzahr, MD, \\ Irene Cybulsky, MD, ${ }^{\mathrm{b}}$ Andre Lamy, MD, ${ }^{\mathrm{b}}$ Lloyd Semelhago, MD, ${ }^{\mathrm{b}}$ and Robert M. K. W. Lee, PhD ${ }^{\mathrm{a}}$
}

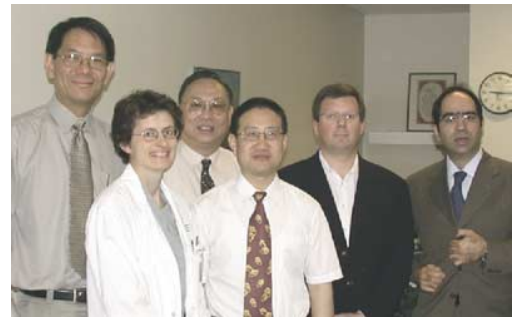

Teoh, Cybulsky, Lee, Gao, Lamy, Abouzahr (left to right)
From the Departments of Anaesthesia, ${ }^{\mathrm{a}}$ Cardiovascular Surgery, ${ }^{\mathrm{b}}$ and Medicine, McMaster University, Hamilton, Ontario, Canada.

This study was supported by the Heart and Stroke Foundation of Ontario, Canada, and the Canadian Institutes of Health Research. Dr Y.-J. Gao is the recipient of the New Investigator Award from the Canadian Institutes of Health Research/Canadian Hypertension Society.

Received for publication April 7, 2005; revisions received May 10, 2005; accepted for publication May 25, 2005.

Address for reprints: Yu-Jing Gao, MD, $\mathrm{PhD}$, Department of Anaesthesia, McMaster University, 1200 Main St West, Hamilton, Ontario, Canada L8N 3Z5 (E-mail: gaoyu@mcmaster.ca).

J Thorac Cardiovasc Surg 2005;130:1130-6

$0022-5223 / \$ 30.00$

Copyright $\odot 2005$ by The American Association for Thoracic Surgery

doi:10.1016/j.jtcvs.2005.05.028
Objective: Recent studies have shown that perivascular adipose tissue from the rat aorta secretes a substance that can dilate the aorta. The purpose of the present study was to examine whether this vasodilator is also present in human internal thoracic arteries.

Methods: Vascular function of human internal thoracic arteries with and without perivascular adipose tissue was assessed with wire myography, and morphology was examined with light microscopy.

Results: The presence of perivascular adipose tissue attenuated the maximal contraction to $\mathrm{U} 46619$ and the contraction to phenylephrine $(1 \mu \mathrm{mol} / \mathrm{L})$ by $37 \%$ and $24 \%$, respectively. Transfer of the solution incubated with a perivascular adipose tissue-intact vessel (donor) to a vessel without perivascular adipose tissue (recipient) induced a significant relaxation (36\%) in the recipient artery precontracted with phenylephrine. Transfer of incubation solution with perivascular adipose tissue alone also induced a relaxation response in the recipient vessel (37\%). The relaxation of the recipient artery induced by the transfer of incubation solution from the donor (artery with intact perivascular adipose tissue or perivascular adipose tissue alone) was absent in vessels precontracted by $\mathrm{KCl}(60 \mathrm{mmol} / \mathrm{L})$ and was prevented by calcium-dependent potassium channel blockers (tetraethylammonium chloride, $1 \mathrm{mmol} / \mathrm{L}$; iberiotoxin, $100 \mathrm{nmol} / \mathrm{L}$ ), but not by the voltage-dependent potassium channel blocker 4-aminopyridine $(1 \mathrm{mmol} / \mathrm{L})$ and the adenosine triphosphatedependent potassium channel blocker glibenclamide $(10 \mu \mathrm{mol} / \mathrm{L})$.

Conclusions: Perivascular adipose tissue in human internal thoracic arteries releases a transferable relaxation factor that acts through the activation of calcium-dependent potassium channels. Because perivascular adipose tissue is often removed in coronary artery bypass grafting, retaining perivascular adipose tissue might be helpful in reducing the occurrence of vasospasm of the graft vessels.

I addition to energy storage, adipose tissue secretes a significant number of biologically active substances, such as leptin, adiponectin, angiotensinogen, resistin, and steroid hormones. ${ }^{1,2}$ Most of the systemic blood vessels are surrounded by a certain amount of perivascular adipose tissue (PVAT) situated outside the adventitial layer. In rat aorta recent studies, including ours, ${ }^{3-5}$ have reported that PVAT releases a relaxing factor that attenuates vascular contractile responses to agonists, including serotonin, angiotensin II, and phenylephrine, through the activation of potassium channels in vascular smooth muscle cells. Hyperpolarization of smooth muscle cell membrane caused by potassium channel activation, as in the case of vascular response to endothelium-derived hyperpolarizing factor (EDHF), is an important mechanism for vasodilation. ${ }^{6}$ However, the fact that rat aortic PVAT can release a relaxation factor does not necessarily mean that PVAT in a human subject would function similarly 
because rodent aorta is surrounded by brown adipose tissue that is absent in adult human subjects. ${ }^{7}$ Therefore the clinical relevance of the finding in rats needs to be examined in human vessels. The purpose of this study is to examine whether this relaxation factor is also present in the PVAT of human arteries.

\section{Methods}

Patients with coronary artery disease who underwent elective coronary artery bypass grafting (CABG) were included in this study. The study conforms to the principles outlined in the Declaration of Helsinki, and institutional approval was obtained.

\section{Vessel Preparation and Contractility Study}

Terminal segments of human internal thoracic arteries (ITAs) that were usually discarded during CABG were collected in oxygenized $\left(95 \% \mathrm{O}_{2}\right.$ and $5 \% \mathrm{CO}_{2}$ ) physiologic salt solution at $4{ }^{\circ} \mathrm{C}$ with the following composition: $\mathrm{NaCl}, 119 \mathrm{mmol} / \mathrm{L} ; \mathrm{KCl}, 4.7 \mathrm{mmol} / \mathrm{L}$; $\mathrm{KH}_{2} \mathrm{PO}_{4}, 1.2 \mathrm{mmol} / \mathrm{L} ; \mathrm{MgSO}_{4}, 1.2 \mathrm{mmol} / \mathrm{L} ; \mathrm{NaHCO}_{3}, 25 \mathrm{mmol} / \mathrm{L}$; $\mathrm{CaCl}_{2}, 1.6 \mathrm{mmol} / \mathrm{L}$; glucose, $11 \mathrm{mmol} / \mathrm{L}$. Care was taken to ensure minimal handling of the ITAs during operation to minimize damage. The ITAs were transported to our laboratory within $60 \mathrm{~min}-$ utes in physiologic salt solution on ice.

Paired ITA rings, one with intact PVAT $\left(\mathrm{PVAT}^{+}\right)$and one with PVAT removed $\left(\mathrm{PVAT}^{-}\right)$, were prepared from each segment. A wired myograph system was used to study the contraction and relaxation responses of the ITAs, as described in our previous report. ${ }^{8}$ ITAs with or without PVAT were studied at the same basal tension. After equilibration for at least 60 minutes, the ITA was challenged with $60 \mathrm{mmol} / \mathrm{L} \mathrm{KCl}$ twice at an interval of 30 minutes to check the viability of the tissue. Concentration-contraction response curve for U $46619(0.3-300 \mathrm{nmol} / \mathrm{L})$ was constructed and expressed as a percentage of $\mathrm{KCl}$ contraction. The concentration that causes $50 \%$ of the maximal contraction was estimated by fitting each concentration-response curve. Relaxation response to sodium nitroprusside was tested in ITAs precontracted with phenylephrine $(1-3 \mu \mathrm{mol} / \mathrm{L})$ and expressed as a percentage of the precontraction value.

\section{Bioassay Experiments and Morphologic Study}

The effects of the relaxing factor released by PVAT were studied in the following way. The donor aliquot was incubated either with ITAs with intact PVAT or with PVAT alone for 20 to 25 minutes and then transferred to the recipient ITAs with PVAT removed. The donor and the recipient ITAs were simultaneously contracted with the same contracting agent $(1 \mu \mathrm{mol} / \mathrm{L}$ phenylephrine or $60 \mathrm{mmol} / \mathrm{L} \mathrm{KCl}$ ), and the transfer of the aliquot was carried out when the contraction of the donor and recipient arteries had reached a plateau. The capacity of the organ bath tube was $4 \mathrm{~mL}$, and the amount of aliquot transferred was $3 \mathrm{~mL}$. The relaxation of the recipient ITAs was expressed as a percentage of the precontraction value. Ion channel blockers were introduced when the relaxation response had reached a plateau. Some ITAs were fixed in $10 \%$ formalin for morphologic studies. Cross-sections of ITAs were stained with hematoxylin and eosin or Gomori trichrome for light microscopy.
TABLE 1. Patient characteristics, including risk factors and medications

\begin{tabular}{lc}
\hline Physical factors & \\
Number & 52 \\
Men, $\mathrm{n}(\%)$ & $44(85)$ \\
Women, $\mathrm{n}(\%)$ & $8(15)$ \\
Age (y) & $62.8 \pm 1.3$ \\
Height (cm) & $172.2 \pm 1.1$ \\
Weight (kg) & $87.4 \pm 2.1$ \\
$\quad$ Overweight, $\mathrm{n}(\%), \mathrm{BMI}$ 25-29.9. & $24(46)$ \\
Obese, $\mathrm{n}(\%), \mathrm{BMI} \geq 30$ & $20(38)$ \\
Health factors, $\mathrm{n}(\%)$ & \\
Hypertension & $32(62)$ \\
Diabetes mellitus & $24(46)$ \\
Hypercholesterolemia & $26(50)$ \\
Smoker & $42(81)$ \\
Myocardial infarction & $39(75)$ \\
Medications, $\mathrm{n}(\%)$ & \\
Aspirin & $33(63)$ \\
Clopidogrel & $14(27)$ \\
$\beta$-Blockers & $39(75)$ \\
ACE inhibitors & $37(71)$ \\
Calcium channel blockers & $21(40)$ \\
Statin & $35(67)$ \\
Nitrates & $43(83)$ \\
\hline
\end{tabular}

$B M I$, Body mass index; $A C E$, angiotensin-converting enzyme.

\section{Statistical Analyses}

Results are presented as means \pm standard error of the mean. Statistical analyses were carried out with SigmaStat (SPSS, Inc, Chicago, Ill). Before statistical testing, normality was examined for all the data, and the minimum $P$ value was .072. The Student $t$ test was used to identify the contractile difference between vessels with or without PVAT in response to $\mathrm{KCl}$ and to phenylephrine. The paired $t$ test was used to assess the relaxation response of the ITAs $\left(\mathrm{PVAT}^{-}\right.$) to transfer of aliquot from ITAs $\left(\mathrm{PVAT}^{+}\right)$and from PVAT alone. Two-way repeated-measures analysis of variance (ANOVA) was used to determine any significant difference between the concentration responses to $U 46619$ in ITAs with or without PVAT. Post hoc $t$ tests were used to identify the concentration at which statistically significant differences occurred, when ANOVA indicated significant differences between $\mathrm{PVAT}^{+}$and $\mathrm{PVAT}^{-}$ITAs. One-way repeated-measures ANOVA was used to assess the effects of $\mathrm{K}^{+}$channel blocker on the relaxation caused by aliquot transfer.

\section{Results}

Patient Characteristics

ITAs from a group of 52 patients consisting mostly of male subjects were studied (Table 1). The average age was 62.8 years, with a range of 43 to 82 years. Forty-six percent of them were overweight, and $38 \%$ were obese. Eighty-one percent of them were smokers. Of the patients, $92.3 \%$ had 1 or more risk factors for coronary heart disease, and $96.2 \%$ were receiving 1 or more type of medication for hypertension, hypercholesterolemia, antianginal therapy, and anti- 

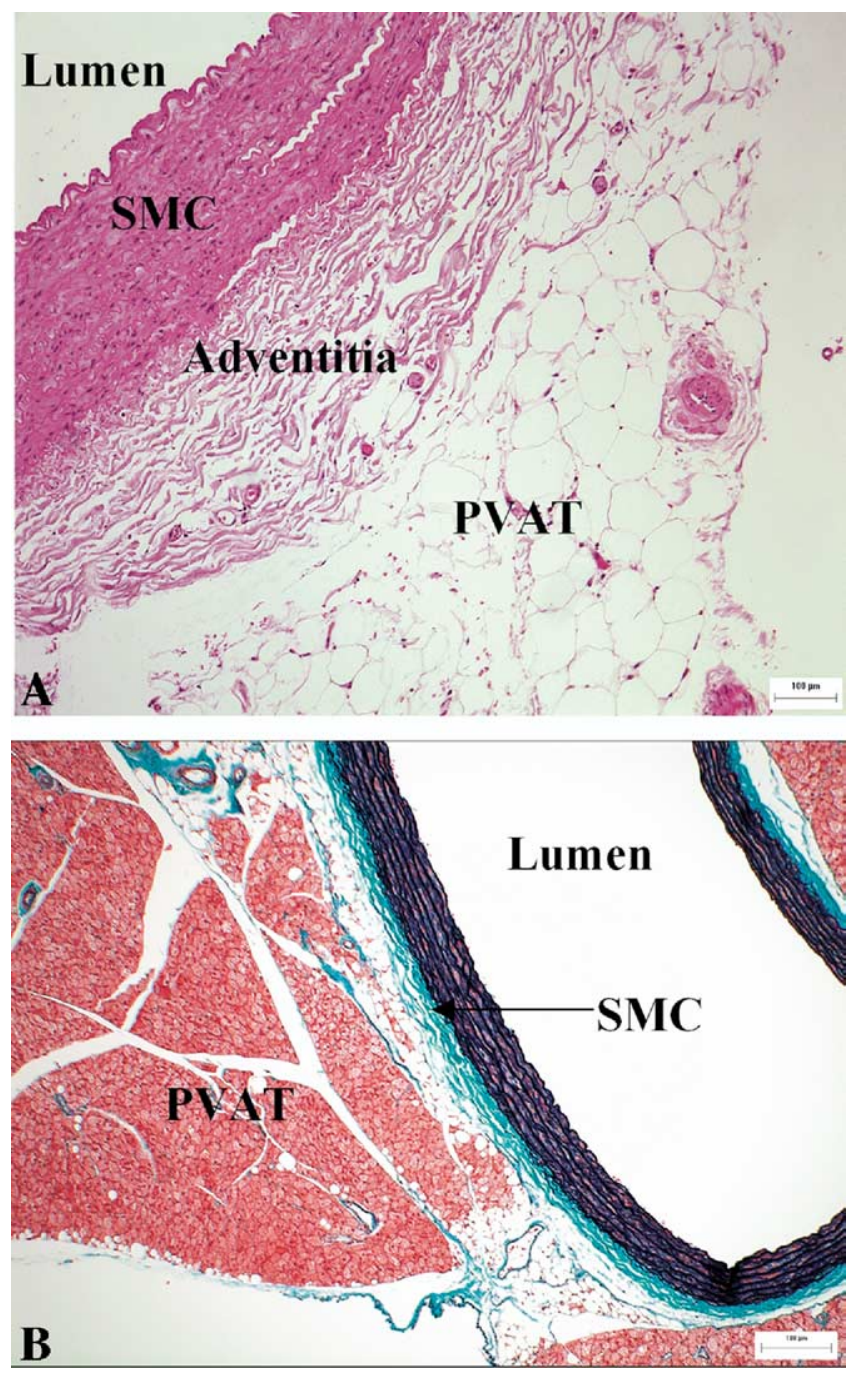

Figure 1. Cross-sections of a human internal thoracic artery (A) and a rat aorta $(B)$ showing the perivascular adipose tissue (PVAT) outside the adventitial layer. Perivascular adipose tissue in human subjects is composed of white adipose tissue compared with brown adipose tissue in rat aortas. SMC, Smooth muscle cell layer. (Magnification bar represents $100 \mu \mathrm{m}$ ).

platelet aggregation medication. Of the ITAs, 92.3\% were treated with papaverine during harvesting. Correlation analysis did not show any relation between the contraction or relaxation response with the patient parameters nor with papaverine treatment (data not shown).

\section{Morphology and Contractile-Relaxation Response}

The human ITA is surrounded by a significant amount of PVAT consisting of white adipose tissue (Figure 1, A) compared with the PVAT of rat aorta, which consists of mostly brown adipose tissue (Figure 1,B). The contraction of ITA in response to $\mathrm{KCl}(60 \mathrm{mmol} / \mathrm{L})$ was not affected by the presence or removal of PVAT (Table 2). Similarly, the relaxation response of ITAs to sodium nitroprusside was also not affected by the removal of PVAT. U 46619, a thromboxane $\mathrm{A}_{2}$ /prostaglandin $\mathrm{H}_{2}$ receptor agonist, induced a concentration-related contraction of the ITA. The presence of PVAT significantly attenuated the contractile response to $\mathrm{U} 46619(P<.001, \mathrm{n}=5-7$ for each $)$, with a $37 \%$ reduction of the maximal contraction (Figure 2 and Table 2), but the value inducing $50 \%$ of the maximal contraction was similar between $\mathrm{PVAT}^{+}$and $\mathrm{PVAT}^{-}$arteries $(3.66 \pm 0.86 \mathrm{nmol} / \mathrm{L}$ in PVAT $^{+}$ITAs vs $3.56 \pm 0.76 \mathrm{nmol} / \mathrm{L}$ in PVAT ${ }^{-}$ITAs; $n=$ $7, P=.9)$. Contraction of ITAs to $1 \mu \mathrm{mol} / \mathrm{L}$ phenylephrine was $23.4 \%$ lower in vessels with PVAT than in those without PVAT (Table 2). When the contraction to phenylephrine had reached a plateau, transfer of bathing solution from ITAs with PVAT to ITAs without PVAT induced a relaxation response in the recipient vessel $(36 \%$ reduction of tension; Figure 3, $A$ and $B$ ). The same transfer procedure between ITAs with PVAT removed did not induce any relaxation response in the recipient vessel (Figure 3,C). Transferring the aliquot incubated with PVAT alone produced a similar relaxation response in the recipient ITAs $(37 \%)$ as in ITAs with intact PVAT (before transfer, 120\% \pm $39 \%$; after transfer, $76 \% \pm 30 \% ; \mathrm{n}=5, P=.014)$. The transfer of solution incubated with PVAT-intact ITAs did not induce relaxation of the recipient ITAs (with PVAT removed) when the ITA was precontracted with $60 \mathrm{mmol} / \mathrm{L}$ $\mathrm{KCl}$ (before transfer, $2.5 \pm 0.4$ tension in grams; after transfer, $2.5 \pm 0.3$ tension in grams; $\mathrm{n}=4, P=.37$ ). The relaxation induced by transfer of aliquots incubated with PVAT-intact ITAs was reversed by the calcium-dependent $\mathrm{K}^{+}$channel blocker tetraethylammonium chloride $(1 \mathrm{mmol} /$ $\mathrm{L}$ ), but not by the voltage-dependent $\mathrm{K}^{+}$channel blocker 4-aminopyridine $(1 \mathrm{mmol} / \mathrm{L})$ and the adenosine triphosphate (ATP)-dependent $\mathrm{K}^{+}$channel blocker glibenclamide (10 $\mu \mathrm{mol} / \mathrm{L}$; Figure 4$)$. Iberiotoxin $\left(10^{-7} \mathrm{~mol} / \mathrm{L}\right)$ mimicked the effects of tetraethylammonium chloride. Heating the aliquots incubated with PVAT-intact ITAs $\left(65^{\circ} \mathrm{C}\right.$ for $10 \mathrm{~min}$ utes) rendered the relaxation factor ineffective, and cyclooxygenase inhibitor (diclofenac, $10^{-5} \mathrm{~mol} / \mathrm{L}$ ) and nitric oxide synthase inhibitor ( $\mathrm{N} \omega$-nitro-L-arginine, $10^{-4} \mathrm{~mol} / \mathrm{L}$ ) did not affect the relaxation effects (data not shown).

\section{Discussion}

To our knowledge, this is the first report that PVAT in human ITAs produces a transferable vasodilating factor, as shown previously in rat aortas. However, the mechanism for the relaxation by this factor is the activation of calciumdependent $\mathrm{K}^{+}$channels in human ITAs, which is in contrast to the activation of ATP-dependent $\mathrm{K}^{+}$channels in rat aortas. The presence of PVAT attenuated the contractile response to agonists (U 46619 and phenylephrine) in human 
TABLE 2. The effects of the presence or absence of perivascular adipose tissue on the contractile and relaxation responses of human internal thoracic arteries

\begin{tabular}{|c|c|c|c|c|}
\hline & PVAT $^{-}$ & PVAT $^{+}$ & $\mathbf{n}$ & $P$ value \\
\hline \multicolumn{5}{|l|}{ Contractile response } \\
\hline $\mathrm{KCl}(60 \mathrm{mmol} / \mathrm{L} ; \mathrm{g})$ & $2.5 \pm 0.3$ & $2.6 \pm 0.3$ & 18 & .76 \\
\hline Phenylephrine $(1 \mu \mathrm{mol} / \mathrm{L} ; \%$ of $\mathrm{KCl})$ & $106 \pm 6.7$ & $81 \pm 7.9$ & 18 & .023 \\
\hline U $46619(0.3 \mu \mathrm{mol} / \mathrm{L} ; \%$ of $\mathrm{KCl})$ & $295 \pm 41$ & $185 \pm 15$ & 7 & .026 \\
\hline \multicolumn{5}{|l|}{ Relaxation response } \\
\hline Sodium nitroprusside (30 $\mu \mathrm{mol} / \mathrm{L} ; \%$ of precontraction) & $99 \pm 7.3$ & $98 \pm 6.7$ & 7 & .9 \\
\hline
\end{tabular}

$\mathrm{PVAT}^{-}$, Absence of perivascular adipose tissue; $\mathrm{PVAT}^{+}$, presence of perivascular adipose tissue.

ITAs. These results suggest that PVAT might play a significant role in the regulation of human vessel tone in vivo.

Endothelium has been recognized as a major regulator of vessel function by releasing various relaxation factors, including nitric oxide and EDHF, and vasoconstrictors, such as endothelin. The possible contribution of PVAT in modulating vessel tone had largely been neglected until recently because in functional studies with isolated vessels, PVAT is routinely removed. This is probably because of the concern that PVAT might interfere with the diffusion of the test agents to the vessel wall and that this might affect the response of the blood vessels. Because the contractile response of the ITA to $\mathrm{KCl}$ or their relaxation response to sodium nitroprusside was similar between $\mathrm{PVAT}^{+}$and PVAT $^{-}$ITAs, the presence of PVAT does not seem to impose any mechanical restraint on the ability of the ITA to contract or relax. However, compared with the responses of PVAT $^{-}$ ITAs, the contractile response of PVAT $^{+}$ITAs to agonists such as U 46619 and phenylephrine was attenuated. This suggested that a relaxation factor is released from PVAT that interferes with the contractile response of the ITA. The notion that a relaxing factor is released by PVAT is supported by the results from our bioassay experiments, which showed that the transfer of bathing solution from ITAs with intact PVAT or PVAT alone to ITAs with PVAT removed caused a relaxation response in the recipient ITAs. The attenuation of the contraction to U 46619 by PVAT might be of particular importance because thromboxane $\mathrm{A}_{2}$ is a potent vasoconstricting agent in the ITA. ${ }^{8,9}$ The thromboxane $\mathrm{A}_{2}$ level is increased during cardiopulmonary bypass ${ }^{10}$ and might thus play a role in vasospasm of the graft artery. ${ }^{11}$ To identify the mechanisms for this relaxation factor from human ITAs, we have focused on $\mathrm{K}^{+}$channels on the basis of the study in rat aortas in which the activation of ATPdependent $\mathrm{K}^{+}$channels was suggested to be the mechanism involved. ${ }^{4}$ Our results showed that in human ITAs the activation of calcium-dependent $\mathrm{K}^{+}$channels is involved instead of the ATP-dependent $\mathrm{K}^{+}$channels because the calcium-dependent $\mathrm{K}^{+}$channel blockers tetraethylammonium chloride and iberiotoxin effectively blocked the relaxation response induced by the bathing solution from ITAs with intact PVAT. Voltage-dependent or ATP-dependent $\mathrm{K}^{+}$ channels do not seem to be involved because 4-aminopyridine, which affects voltage-dependent $\mathrm{K}^{+}$channels, and glibenclamide, which affects ATP-dependent $\mathrm{K}^{+}$channels, did not affect this relaxation response. It has been reported that EDHF induces relaxation through activation of calcium-dependent $\mathrm{K}^{+}$channels in human ITAs. ${ }^{6}$ Therefore PVAT-derived relaxation factor showed some similarity to EDHF in its action.

The identity of the PVAT-derived relaxation factor remains unclear. The lack of effects of cyclooxygenase or nitric oxide synthase inhibitor on this relaxation factor has

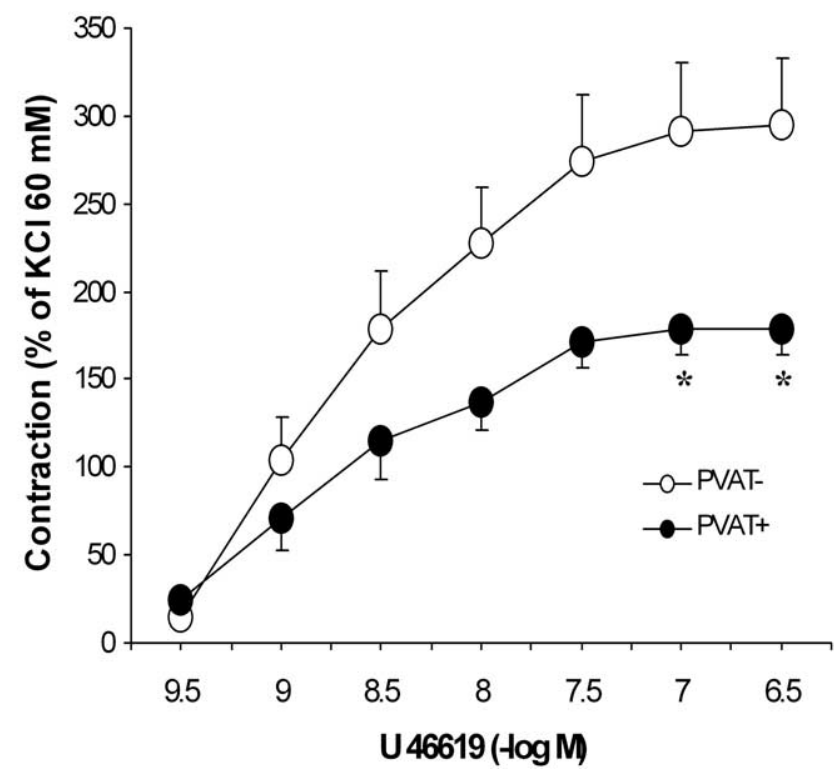

Figure 2. Concentration-response curve to $U \mathbf{4 6 6 1 9}$ in perivascular adipose tissue-intact $\left(\mathrm{PVAT}^{+}\right)$and perivascular adipose tissue-denuded (PVAT-) preparations of human internal thoracic arteries. Contraction to $U \mathbf{4 6 6 1 9}$ was attenuated in perivascular adipose tissue-intact preparations $(P<.001$, 2-way ANOVA). The maximal contraction to $U \mathbf{4 6 6 1 9}$ was reduced in perivascular adipose tissue-intact arteries $(P=.026, n=7$ for each). 


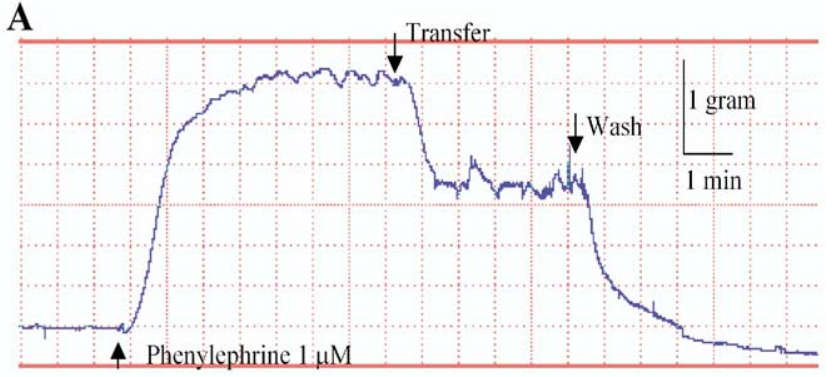

B

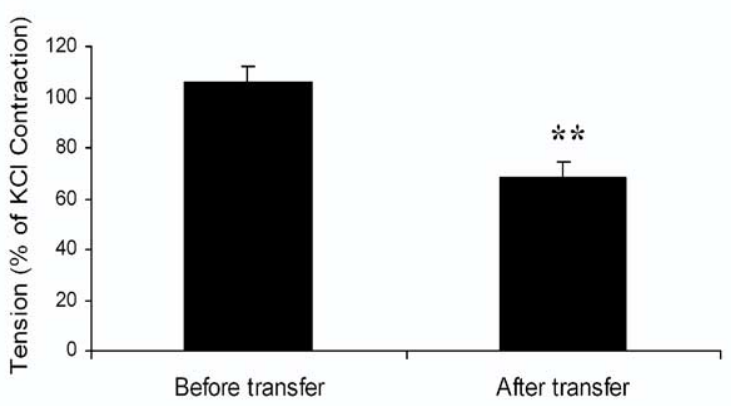

C

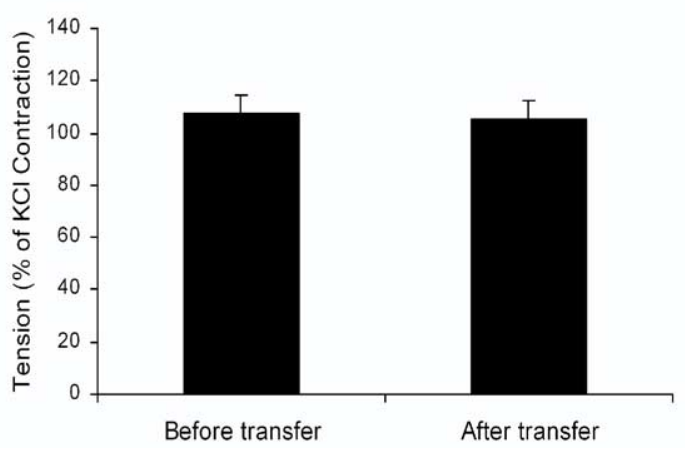

Figure 3. Transferring aliquots incubated with perivascular adipose tissue-intact human internal thoracic artery tissue to perivascular adipose tissue-denuded preparations induced a marked relaxation in the recipient artery. $A$, Typical relaxation response of recipient artery; $B$, a summary of relaxation response ${ }^{* *} \boldsymbol{P}<.001$ vs tension before transfer, $\mathbf{n}=18$ for each); and $C$, transfer of aliquot between perivascular adipose tissue-denuded arteries in the control subjects ( $P=.55, \mathrm{n}=4$ for each).

also ruled out the involvement of endothelial prostaglandins or nitric oxide. Adipocytes produce a number of adipokines, ${ }^{1,2}$ and some of the adipokines, such as angiotensinogen, might have the potential to regulate vessel function. The fact that this relaxation factor is deactivated by heating suggests that this might be a peptide, which is similar to the finding by Lohn and associates. ${ }^{4}$

The types of adipose tissue surrounding rat aorta and human ITAs are different, being brown in rats and white in
A

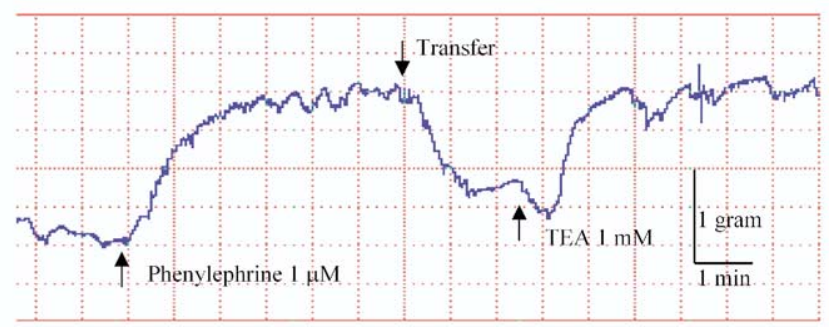

B

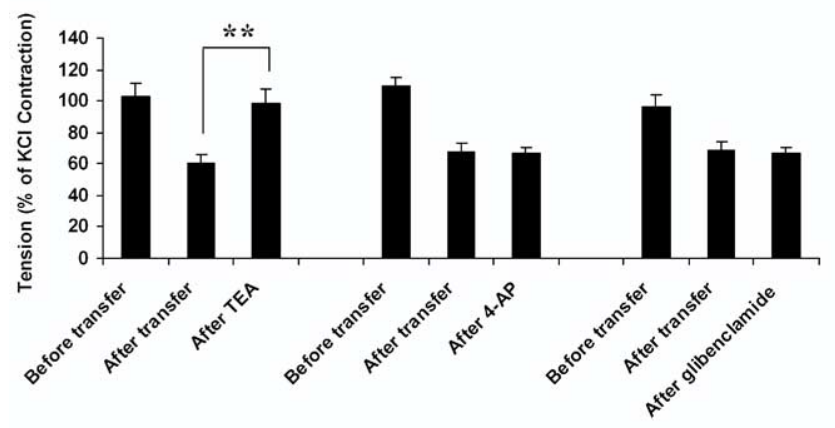

Figure 4. Effects of potassium channel blockers on relaxation response of perivascular adipose tissue-denuded human internal thoracic arteries induced by aliquot transfer from perivascular adipose tissue-intact arteries. A, Typical recording showing tetraethylammonium chloride (TEA) reversed the relaxation; $B$, summary of the effects of various $\mathrm{K}^{+}$channel blockers. Tetraethylammonium chloride $\left.{ }^{* *} P<.001, \mathrm{n}=13\right)$, but neither 4-aminopyridine (4-AP, $P=.98, \mathrm{n}=3$ ) nor glibenclamide $(P=.91$, $\mathrm{n}=3$ ), reversed the relaxation response.

human subjects. However, our present study in human ITAs and previous studies in rat aortas suggested that both brown and white PVAT has the ability to produce a relaxation factor. The difference in the subtypes of $\mathrm{K}^{+}$channels activated by this factor might represent difference between brown and white PVAT or the density of different subtypes of $\mathrm{K}^{+}$channels in human vessels versus rat aortas.

The human ITA is a better graft choice than veins in CABG in terms of graft patency and patient survival ${ }^{12}$ because of its high resistance to atherosclerosis. ${ }^{13}$ However, one complication with the use of the ITA is the occurrence of vasospasm, ${ }^{14,15}$ which might occur during or after surgical intervention and might result in myocardial infarction and postoperative morbidity. ${ }^{16}$ The mechanisms of the spasm are not fully understood, but surgical traumainduced release of various vasoconstricting substances, reduced production of vasodilating substances, or both might 
be important contributing factors. Various pharmacologic agents are used to counteract the spasm or to dilate the ITA,${ }^{14}$ but some of these agents, such as papaverine, are harmful to endothelial and smooth muscle cells. ${ }^{8,17} \mathrm{Al}-$ though the long-term consequence of the damage to vascular tissue by papaverine is not known, it is prudent to develop alternatives to prevent the occurrence of the spasm. We suggest, on the basis of the present study, that retaining PVAT in the ITA for CABG might help to alleviate the contraction of the ITA to stimulating agents and therefore might be helpful in reducing the occurrence of vasospasm.

During CABG, the ITA is harvested either as a pedicle with the surrounding tissues intact, which include the veins, lymphatics, and nerves, or these tissues are removed in a process known as skeletonization, as first described by Keeley ${ }^{18}$ in 1987. The advantages of the skeletonization procedure are longer vessel length for grafting and minimized chest-wall trauma with reduced risk of sternal wound infection because vein, muscle, and accompanying endothoracic tissues are left in place and collateral sternal blood supply is preserved. Blood flow was reported to be higher in skeletonized ITAs than in pedicled ITAs after surgical intervention. ${ }^{19-22}$ Most of the long-term follow-up studies of patients who underwent CABG involving skeletonized ITAs were focused on postoperative mortality and morbidity, ${ }^{23}$ safety in elderly patients, ${ }^{24,25}$ and diabetic and obese patients. ${ }^{26,27}$ However, it remains to be determined whether the presence of PVAT in ITAs will confer additional longterm benefits to the patient in terms of vascular integrity and functions. The presence of PVAT might be more advantageous to more reactive arteries, such as radial arteries, than ITAs to enhance vessel relaxation after CABG.

In summary, we have demonstrated here for the first time that PVAT attenuates human ITA contraction by releasing a transferable relaxing factor that activates calcium-dependent $\mathrm{K}^{+}$channels. This understanding will not only add new insight to the regulation of vascular tone in the human ITA but might have potential implications in our efforts to prevent vasospasm of the ITA during and after CABG. We suggest that retaining PVAT in ITA grafts might help to alleviate wall tension by preserving the production of this relaxation factor from PVAT and also might help to reduce surgical trauma to the graft tissue. Prevention of vasospasm and improvement of blood flow will have a major benefit in strategies aimed at increasing the long-term patency of such grafts.

We thank Ms Mary Helen Blackall for her assistance in the collection of the ITAs from surgical patients, Dr Qi Zhou for her advice on statistical analyses, and Miss Nina Li and Mr Nathan $\mathrm{Ni}$ for their technical assistance.

\section{References}

1. Engeli S, Schling P, Gorzelniak K, Boschmann M, Janke J, Ailhaud G, et al. The adipose-tissue renin-angiotensin-aldosterone system: role in the metabolic syndrome? Int J Biochem Cell Biol. 2003;35:807-25.
2. Guerre-Millo M. Adipose tissue hormones. J Endocrinol Invest. 2002; 25:855-61.

3. Dubrovska G, Verlohren S, Luft FC, Gollasch M. Mechanisms of ADRF release from rat aortic adventitial adipose tissue. Am J Physiol Heart Circ Physiol. 2004;286:H1107-13.

4. Lohn M, Dubrovska G, Lauterbach B, Luft FC, Gollasch M, Sharma AM. Periadventitial fat releases a vascular relaxing factor. FASEB $J$. 2002;16:1057-63.

5. Gao YJ, Holloway AC, Zeng Z, Lim GE, Petrik JJ, Foster WG, et al. Prenatal exposure to nicotine causes postnatal obesity and altered perivascular adipose tissue function. Obes Res. 2005;13: 687-92.

6. Archer SL, Gragasin FS, Wu X, Wang S, McMurtry S, Kim DH, et al. Endothelium-derived hyperpolarizing factor in human internal mammary artery is 11,12-epoxyeicosatrienoic acid and causes relaxation by activating smooth muscle BK(Ca) channels. Circulation. 2003;107: 769-76.

7. Cinti S. The adipose organ: morphological perspectives of adipose tissues. Proc Nutr Soc. 2001;60:319-28.

8. Gao YJ, Yang H, Teoh K, Lee RM. Detrimental effects of papaverine on the human internal thoracic artery. J Thorac Cardiovasc Surg. 2003;126:179-85.

9. He GW, Rosenfeldt FL, Buxton BF, Angus JA. Reactivity of human isolated internal mammary artery to constrictor and dilator agents. Implications for treatment of internal mammary artery spasm. Circulation. 1989;80:I141-50.

10. Davies GC, Sobel M, Salzman EW. Elevated plasma fibrinopeptide A and thromboxane B2 levels during cardiopulmonary bypass. Circulation. 1980;61:808-14.

11. He GW, Yang CQ. Effect of thromboxane A2 antagonist GR32191B on prostanoid and nonprostanoid receptors in the human internal mammary artery. J Cardiovasc Pharmacol. 1995;26:13-9.

12. Loop FD, Lytle BW, Cosgrove DM, Stewart RW, Goormastic M, Williams GW, et al. Influence of the internal-mammary-artery graft on 10-year survival and other cardiac events. $N$ Engl J Med. 1986;314: $1-6$.

13. Sims FH. A comparison of coronary and internal mammary arteries and implications of the results in the etiology of arteriosclerosis. Am Heart J. 1983;105:560-6.

14. Rosenfeldt FL, He GW, Buxton BF, Angus JA. Pharmacology of coronary artery bypass grafts. Ann Thorac Surg. 1999;67:878-88.

15. Sarabu MR, McClung JA, Fass A, Reed GE. Early postoperative spasm in left internal mammary artery bypass grafts. Ann Thorac Surg. 1987;44:199-200

16. Sasson L, Cohen AJ, Hauptman E, Schachner A. Effect of topical vasodilators on internal mammary arteries. Ann Thorac Surg. 1995; 59:494-6.

17. Gao YJ, Stead S, Lee RM. Papaverine induces apoptosis in vascular endothelial and smooth muscle cells. Life Sci. 2002;70:2675-85.

18. Keeley SB. The skeletonized internal mammary artery. Ann Thorac Surg. 1987;44:324-5.

19. Gaudino M, Trani C, Glieca F, Mazzari MA, Rigattieri S, Nasso G, et al. Early vasoreactive profile of skeletonized versus pedicled internal thoracic artery grafts. J Thorac Cardiovasc Surg. 2003; 125:638-41.

20. Deja MA, Wos S, Golba KS, Zurek P, Domaradzki W, Bachowski $\mathrm{R}$, et al. Intraoperative and laboratory evaluation of skeletonized versus pedicled internal thoracic artery. Ann Thorac Surg. 1999; 68:2164-8.

21. Wendler O, Tscholl D, Huang Q, Schafers HJ. Free flow capacity of skeletonized versus pedicled internal thoracic artery grafts in coronary artery bypass grafts. Eur J Cardiothorac Surg. 1999;15:247-50.

22. Takami Y, Ina H. Effects of skeletonization on intraoperative flow and anastomosis diameter of internal thoracic arteries in coronary artery bypass grafting. Ann Thorac Surg. 2002;73:1441-5.

23. Bical O, Braunberger E, Fischer M, Robinault J, Foiret JC, Fromes Y, et al. Bilateral skeletonized mammary artery grafting: experience with 560 consecutive patients. Eur J Cardiothorac Surg. 1996;10:971-5.

24. Kramer A, Mastsa M, Paz Y, Locker C, Pevni D, Gurevitch J, et al. Bilateral skeletonized internal thoracic artery grafting in 303 pa- 
tients seventy years and older. J Thorac Cardiovasc Surg. 2000; 120:290-7.

25. Kramer A, Mohr R, Lev-Ran O, Braunstein R, Pevni D, Locker C, et al. Midterm results of routine bilateral internal thoracic artery grafting. Heart Surg Forum. 2003;6:348-52.

26. Gurevitch J, Paz Y, Shapira I, Matsa M, Kramer A, Pevni D, et al.
Routine use of bilateral skeletonized internal mammary arteries for myocardial revascularization. Ann Thorac Surg. 1999;68:406-11.

27. Matsa M, Paz Y, Gurevitch J, Shapira I, Kramer A, Pevny D, et al. Bilateral skeletonized internal thoracic artery grafts in patients with diabetes mellitus. J Thorac Cardiovasc Surg. 2001;121: 668-74. 